\title{
Spiritual Obsession and its Influence on Behavioral Aspects of Students
}

\author{
Jagadeesh Rajashekharaiah* \\ Dean - Academics \& Professor - Operations \& Chief Editor of the SDMIMD Journal of Management, India
}

Submission: November 24, 2017; Published: December 04, 2017

*Corresponding author: Jagadeesh Rajashekharaiah, Dean - Academics \& Professor - Operations \& Chief Editor of the SDMIMD Journal of Management, India, Tel: 9945155055; Fax: 0821-2425557; Email: jagadeeshraj@sdmimd.ac.in

\section{Opinion}

\section{Observations on spiritual obsession}

In India, spiritualism is closely interlinked with religion When someone is described as spiritually oriented or practicing spirituality, it can be understood as the person is detached from the mundane or the routine things or practices. But the more common perception is the person is more a serious follower of religious customs and traditions

\section{Introduction}

Human beings are known to yield to temptations. The best quote about temptations is by Oscar Wilde, who said "I can resist anything but temptation". To yield to temptations though is considered a normal reaction by a majority of people, and offering resistance to temptations perhaps is seen as a losing battle. History is full of such falls as experienced by famous people. But the question here is, when once people yield to temptations, do they repeat it several times, perhaps to an extent of not being able to abandon it. Thus, what can happen once as a matter of chance has all the probability of repeating itself several times. This leads to a voluntary submission to all the temptations and culminates in obsession. When a person compulsively engages in the act of pursuing the most cherished or desirous activity, the stage is perhaps the point of no return. This stage is dreaded because no $\mathrm{U}$ - turn is possible.

The journey from an occasional use to a habitual use and reaching a stage of compulsive use takes different times for different persons. If the word "use" is substituted by "practice" or "consumption" then the stage is set for obsession. In this article the author wants to share his own observations and experience with respect to the behavioral changes as seen on one group of people namely the students who would have come under the influence of spiritual practices. The author being an academician from the last more than three decades had ample opportunities to observe the behavioral changes in those students who followed the spiritual practices to a greater extent.

\section{Has spiritual obsession been properly defined?}

The word spirit is extensively used as a metaphor to describe an attitude or willingness and also to describe the invisible energy or persona that is not physical in form but can manifest in different manners. For example the spirit of fight could be a person's undefeatable attitude or mental power that is only observed or felt but not seen in any physical form. Hence when one follows the spiritual concept where the body is considered as a mere physical form containing an energy source inside, the chances are the question of life doesn't exist between birth and death, rather beyond the calendar life. Thus people believe in the spirit that is considered eternal and death occurring only to the physical body but not to the spirit inside. As stated in the dictionary, the origin of the word spiritual is from Middle English, from Anglo-French \& Late Latin; and derived from Late Latin spiritualis, of breathing, of wind, from spiritus. Further the meaning of the word "spiritual" in the Merriam - Webster Dictionary, is listed as follows:

a) of or relating to a person's spirit

b) of or relating to religion or religious beliefs

c) having similar values and ideas: related or joined in spirit

When people start following religious practices, liking or otherwise, the spiritual dimension assumes a greater role. Here the person is considered to be above the usual earthly people who adopt different religious or non-religious practices with an eye on the revenue. As in any other case, the spiritual dimension is more often not measurable and hence linked to a person's behavior. Because the behavioral aspects are easily identifiable and comparable with similar practices followed by others, the person's overall characterization becomes easier. In typical Indian families the religious traditions or customs are taught right from the early childhood and the parents quite often impose the religious practices upon their children with 
strict monitoring and control. As a result the children start chanting religious prayers, indulge in certain rituals, and even following certain food styles.

These regulations further extend to the language to be used while conversing inside home, the body postures, time of sleep or eating, and later to even I developing relationships. The parents from their own learning's or beliefs create a kind of a pattern or systematic framework within which the children have to move and remain obedient. In some communities, fasting on during religious celebrations, eating only a particular type of food on certain days, or even dressing in a prescribed style during festivals associated with religious practices. In fact in some cases the children are asked to have some kind of a marking on their faces, to distinguish them from others who may not be so religious in following the customs. Children who grow up obeying the restrictions or practices prescribed by their parents tend to be either softer in nature in the early formative years, say till their schooling years.

But later, the same kids during their college days or during their higher education may tend to defy all such restrictions and even stat rebelling against such impositions. It is this delicate stage that needs to be carefully observed and monitored by the educators. As such behavioral changes may have serious ramifications with the passage of time. In fact the teenagers are highly susceptible for such changes and in the extreme situations may become radicalized to the extent of blind faith leading to irrational behavior. Taylor [1] states that obsession with spirituality could have harmful effects for the individual and also on his/her family.

The radicalized youth have all the possibility of committing acts that could be anti-social or in human thereby incurring the wrath of the society. Educators can very well observe these kinds of changes and hence are the right persons to guide them towards correctional procedures.

Students who brazenly exhibit their displeasure towards accepted norms, or who show intolerance towards others, or who feel superior to all others, definitely need to be carefully watched and properly counseled to avoid any kind of hasty acts. Sometimes such students display their attitude by wearing certain types of clothes, tattoos on their body parts with some strange symbols or slogans or indecipherable messages. These could also be some visible signs that such students have taken their spiritual obsession to the highest level. As long as these do not disturb the peace or cause any danger, they can be ignored. But if they are likely pose threats to others or likely to cause any harm, then appropriate corrective actions may be necessary. Robson [2] quoting the results from a survey comments that people with spiritual orientation may have worse mental health compared to non-spiritually or nonreligiously oriented people.

\section{Conclusion}

Spiritual obsession at best may be thought as another trendy life style perhaps as a fad among a few people. But the educators need to observe the students and ensure their behavior is not influenced by the strong spiritual views so as to cause hatred or animosity among the student community. But like any other obsession, if spiritual obsession is controlled in the beginning, it may not manifest into any harmful repercussions.

\section{References}

1. Taylor C (2002) Religious Addiction: Obsession with Spirituality. Pastoral Psychology, Virginia, 50(4): 291-315.

2. Robson Steve (2013) Spiritual people are more likely to be mentally ill (but at least they think life has more meaning).

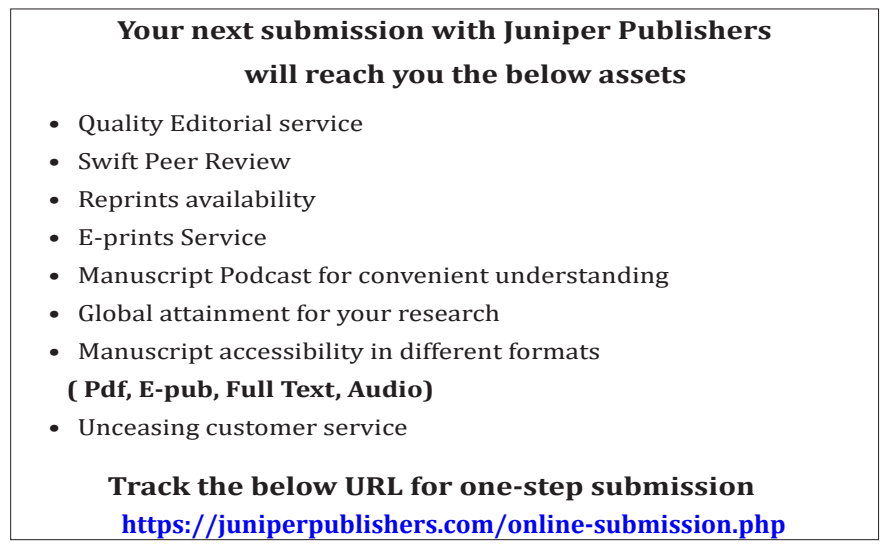

